\title{
Predicting earthquake risks
}

\section{San Francisco}

FoR the first time, scientists are planning to assemble a comprehensive model of the earthquake hazards for a single earthquakeprone region. Focusing on Southern California and integrating 30 years' worth of data from disparate sources, researchers at the newly established Southern California Earthquake Center (SCEC) hope to improve earthquake forecasting and help to predict the strength of ground motions in specific locations in the Los Angeles area.

In particular, this 'master model' should help emergency planners and urban developers, as well as Earth scientists, to attain a better understanding of exactly what earthquake hazards exist in which areas of Southern California.

Although scientists at scores of institutions study California's frequent tremors, no one has ever attempted comprehensive seismic predictions or maps of hazard zones for the region, says SCEC's executive director, Thomas Henyey. But with $\$ 5$ million from the National Science Foundation (NSF) and the United States Geological Survey (USGS) in its first-year budget, and an expected 5-11 years of support as an NSF Science and Technology Center, the centre plans to change that. Located at the University of Southern California, it will draw on scientists from seven universities and the USGS.

The model will undoubtedly require much new research, but adequate data already exist to develop rudimentary hazard analysis maps, Henyey says. And with refinement, the maps may serve very practical purposes.
"Soon, we hope you'll be able to come to us as a developer and ask what is the probability of a quake on a particular property and how strong the ground motion will be", he says. "Our goal is to give you our best description of the quake hazard that will be location-specific."

The database will also be used by the National Earthquake Prediction Evaluation Council to improve both short-term and long-term earthquake predictions, says California state geologist James Davis, a member of the council. In addition, SCEC will probably collaborate with the National Center for Earthquake Engineering Research at the State University of New York in Buffalo, another NSF-funded centre.

Henyey expects the centre to take at least two years to integrate existing earthquakerelated data into a useful form. The research areas that will be important to the centre's master model include the history of fault movements, earthquake statistics, patterns of strain buildup and crust deformation, physical properties of earthquake sources and descriptions of surface shaking in response to seismic waves. Once the database is complete, it will be used to help guide the centre's future research directions, but SCEC is already reviewing the nearly 40 research proposals it has received from interested scientists, and it expects to make funding decisions on them in the next few weeks.

The SCEC may have a Northern California counterpart soon, Davis says. Researchers in the San Francisco Bay area are considering development of a similar organization for their region, which, like Southern
California, is populous, prone to earthquakes and well studied by Earth scientists.

SCEC is set up as a 'center without walls' - an organization of people in many institutions rather than in a single location. In addition to USC and the USGS, the centre's participants include the California Institute of Technology, the University of California at the campuses of Los Angeles, San Diego, Santa Barbara and Santa Cruz, and Columbia University's Lamont-Doherty Geological Observatory in New York.

Elizabeth Schaefer

PASTEUR INSTITUTE

\section{New building defies the metro}

Paris

THE French Prime Minister, Michel Rocard, last week inaugurated a new retrovirus building at the Pasteur Institute in Paris. Costing FF100 million, the 4,685square-metre building was paid for entirely by funds raised by the institute since 1987 .

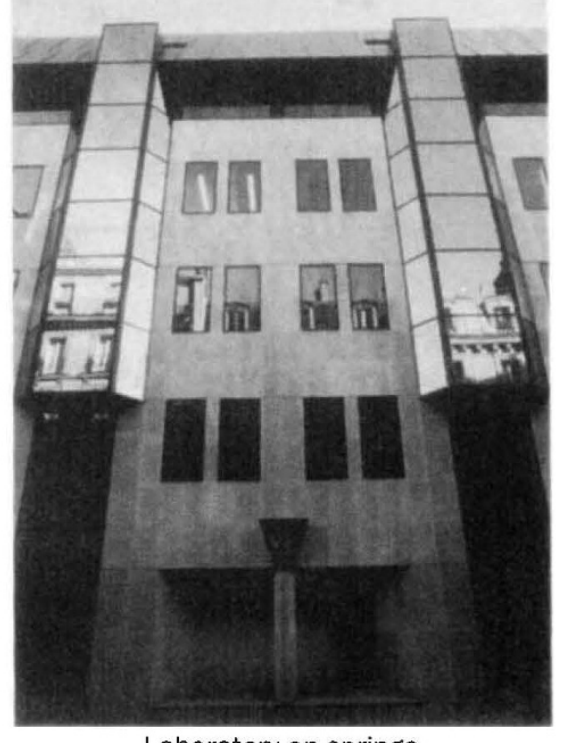

Laboratory on springs.

There are ten laboratories with space for 120 researchers and the same number of technicians and administrators, mostly working on AIDS.

The building incorporates some unusual features. The whole structure, which weighs 12,800 tonnes, is supported on 246 massive springs whose function is to absorb vibrations from a Paris metro line that runs just a few metres from the foundations. And to make sure viral material does not escape into the atmosphere, each of the four maximum-security laboratories has total air filtering, special extractors and autoclaves, and is kept below ordinary atmospheric pressure.

Since 1984, spending on AIDS research at the Pasteur has increased by a factor of six and accounts for about one-fifth of the FF600-million annual budget in 1990 .

Peter Coles 